\title{
Decisions, decisions: Chocolate, vanilla, or something else?
}

\author{
Thoralf M. Sundt, MD
}

\author{
From the Division of Cardiac Surgery, Massachusetts General Hospital; and Department of Surgery, Harvard \\ Medical School, Boston, Mass. \\ Disclosures: Author has nothing to disclose with regard to commercial support. \\ Received for publication Oct 26, 2015; accepted for publication Oct 26, 2015; available ahead of print Dec 1, \\ 2015. \\ Address for reprints: Thoralf M. Sundt, MD, Division of Cardiac Surgery, Massachusetts General Hospital, \\ 55 Fruit St, Boston, MA 02114 (E-mail: tsundt@mgh.harvard.edu). \\ J Thorac Cardiovasc Surg 2016;151:339-40 \\ $0022-5223 / \$ 36.00$ \\ Copyright (C) 2016 by The American Association for Thoracic Surgery \\ http://dx.doi.org/10.1016/j.jtcvs.2015.10.103
}

This study, from what must be considered a reference center for the treatment of patients with Marfan syndrome, ${ }^{1}$ provides useful information for selecting the right procedure for an individual patient. The essentially simultaneous insight by Yacoub $^{2}$ and David ${ }^{3}$ that it was unnecessary to discard healthy aortic cusps simply because they had the misfortune to be supported by an unhealthy aortic wall, combined with their creative genius and technical virtuosity, established what has become a super-subspecialty within cardiac surgery. Yacoub's remodeling procedure and David's more popular reimplantation technique are attractive to surgeons and patients alike; the former for their technical elegance and the latter for their promise of a durable solution without anticoagulation. The technical aspects are becoming more refined, and as confidence builds their application is growing to include even those patients with acute dissection in many centers.

Despite this progress, there remain questions about patient selection in general and about the Marfan population in particular. Patients with Marfan syndrome are often young individuals with the most to gain from a warfarinfree solution, yet they also violate the central rationale for the procedure: Their aortic cusps are not normal. ${ }^{4}$ Durability of the procedure among patients free of apparent connective tissue disorder is almost universally encouraging; however, data for those with Marfan syndrome are a bit more mixed. This uncertainty means that, when faced with decision making around the surgical procedure to be performed in a patient with Marfan syndrome, we are still balancing known durability of mechanical valves at the cost of anticoagulation, versus unclear durability of the repair option. The results of this study ${ }^{1}$ inform this decision to a significant extent, but do not settle the matter. It would be wrong to interpret the results as demonstrating the superiority of the valve-sparing option, and the authors have been careful not to make such a claim.

The authors display technical excellence, a balanced approach, fine clinical judgment, and frank honesty. Their remarkable operative outcomes are what we have come to expect from the practice established by Vincent Gott, with

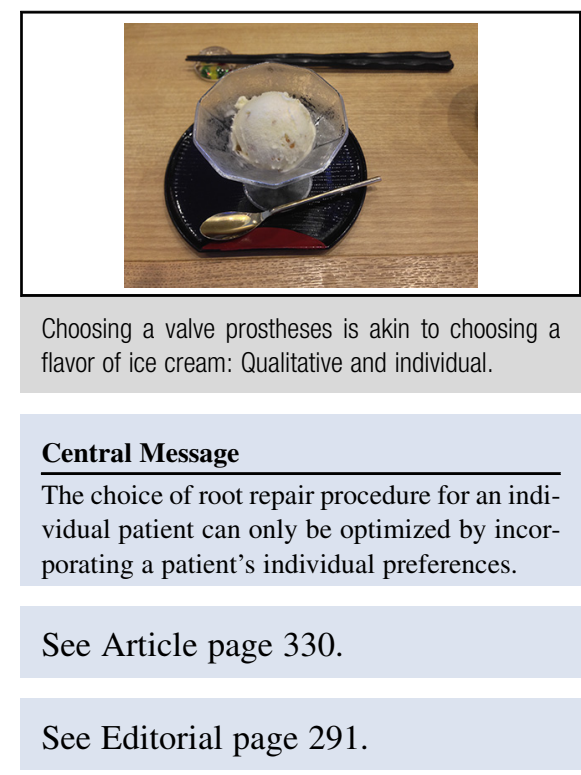

no mortalities despite the inclusion of patients with acute dissection. Their findings suggest similar long-term survival but with a higher rate of hemorrhagic and thromboembolic complications when a Bentall is used. The latter is expected given the requisite anticoagulation for mechanical prostheses, whereas the former might be anticipated given contemporary clinical cardiologic care. In this study, as in many others comparing mechanical versus xenograft valves, there is no easy answer based on survival to the question "which approach is better?" Others might disagree about the softer end points. Didn't the higher rate of hemorrhagic and embolic complications demonstrate the valve-sparing root replacement (VSRR) option to be superior to the Bentall? Not so fast.

Late follow-up of surgical patients in the United States is challenging. The population is mobile and government regulations concerning patient contact are cumbersome. The result is often incomplete ascertainment of outcomes. In this case we lack adequate information on late valve performance. The authors ${ }^{1}$ had recent telephone contact with $70 \%$ of patients and echocardiography in $84 \%$, and at only a median of 2 years compared with almost 8 years of clinical follow-up. It is true that reoperation rates look low, but it is well recognized that many factors enter into the decision to operate or not to operate. This study would be more valuable if the authors could obtain more complete echocardiography information; without it, we simply do not have all the data we need to fairly compare outcomes of the procedures.

There is another, more subtle point to be made. This study should not be considered a comparison of procedures: 
It is a comparison of the results of the application of procedures nuanced by expert clinical judgment in a patient-centered (ie, individualized) manner. The procedures were neither randomly nor universally appliedthey were selectively applied. Patients with annular diameter $>34 \mathrm{~mm}$, significant leaflet fenestrations, significant leaflet asymmetry, and acute dissection did not get VSRR. The patients undergoing VSRR also less frequently had severe aortic regurgitation. It is also likely that some patients opted for the mechanical valve. Accordingly the distribution of procedures was a 60/40 split between VSRR and Bentall, respectively. This study is not about doing VSRR on every patient, but about results achieved with both options when applied to properly selected patients.

This brings us to my central message: The choice among valve procedures involves trade-offs that are qualitatively as well as quantitatively different. It is often a choice between the risks associated with anticoagulation and the risk of requiring reoperation, without hard survival advantages to tip the balance. Because it is patients who live with those risks, it is only patients who can express their preferences. A surgeon can no more make that determination for a patient than he or she can make the choice for the patient between chocolate and vanilla ice cream. This study reassures me that neither choice is wrong.

\section{References}

1. Price J, Magruder JT, Young A, Grimm JC, Patel ND, Alejo D, et al. Long-term outcomes of aortic root operations for Marfan syndrome: A comparison of Bentall versus aortic valve-sparing procedures. J Thorac Cardiovasc Surg. 2016;151:330-8.

2. Sarsam MA, Yacoub M. Remodeling of the aortic valve anulus. J Thorac Cardiovasc Surg. 1993;105:435-8.

3. David TE, Feindel CM. An aortic valve-sparing operation for patients with aortic incompetence and aneurysm of the ascending aorta. J Thorac Cardiovasc Surg. 1992; 103:617-22.

4. Fleischer KJ, Nousari HC, Anhalt GJ, Stone CD, Laschinger JC. Immunohistochemical abnormalities of fibrillin in cardiovascular tissues in Marfan's syndrome. Ann Thorac Surg. 1997;63:1012-7. 